\title{
Evaluation of Faculty Performance of Higher Education Institution Using Principal Component Analysis
}

\author{
Mamatha $\mathbf{H} . \mathrm{K}^{1, *}$, Sridhar $\mathbf{R}^{2}$, Balasubramanian $\mathrm{S}^{3}$ \\ ${ }^{1}$ Department of Health System Management Studies, JSS Academy of Higher Education \& Research, India \\ ${ }^{2}$ Sri Ramakrishna Mission Vidyalaya, Coimbatore, India \\ ${ }^{3}$ Faculty of Life Sciences, JSS Academy of Higher Education \& Research, India
}

Received May 30, 2019; Revised September 26, 2019; Accepted October 5, 2019

Copyright $\odot 2019$ by authors, all rights reserved. Authors agree that this article remains permanently open access under the terms of the Creative Commons Attribution License 4.0 International License

\begin{abstract}
Education is one of the drivers of economy and the role of higher education institutions (HEIs) as knowledge contributors to the nation's economy is significant. Educational organisations being service organizations quality of service depends directly on the capability, commitment, and motivation of faculty who provide it and ensuring quality is a challenge for education managers. One method of ensuring quality is by assessing the performance of faculty and ranking them based on their performance against set standards-Academic Performance Indicators. Teachers of modern education system have to carry out multiple tasks- administrative, teaching, research, societal engagement, mentoring, extra-curricular activities and so on. Hence, setting standards for each of these activities and measuring them on the same yardstick may not yield desired results. This is especially true in multidisciplinary institutions wherein faculty have different tasks and roles as per their specialization and discipline. Therefore, conventional assessment criteria may not suffice the decision makers of educational institutions. Principal Component analysis (PCA) is a standard statistical technique that can be used to reduce the dimensionality of a data set by assessing the dimensional structure of a dataset (Dunteman, 1989) and reducing a large number of variables into a smaller set of linear combinations (components). PCA is a variable reduction method that can be used to reduce the multiple variables in the performance appraisal criteria and result in smaller dataset for further analysis. In this study, the faculty performance scores (API) as per UGC format were analysed using PCA and the most important components were identified contributing to the performance of faculty.
\end{abstract}

Keywords Higher Education Institutions, Faculty Performance Appraisal, PCA

\section{Introduction}

In higher education institutions assessing faculty performance across various disciplines is a challenge as the nature of work differs from faculty to faculty. Evaluation of their performance has to encompass all the parameters which reflect their nature of work and the multiple roles carried out by them to yield acceptable results. The traditional methods for evaluation may not capture all the contributions by them and hence may not yield acceptable results thereby contributing to dissatisfaction and demotivation among faculty. With the challenges in HEI, teaching profession has become very complicated. Tripathi et al., [1] stated that the role of a faculty member is no more a knowledge transferring process; but it has become a knowledge sharing process. In modern education, teaching is a complex activity with operational area and it relies on clearly defined set of competencies possessed by professionals working in this field [2].

To ensure the quality of HEIs, a well-qualified and highly-motivated faculty is critical [3]. Developing highly-motivated and well-qualified faculty requires well-established mechanisms to evaluate their performance $[3,4]$. In spite of growing interest in the area of performance appraisal of faculty literature does not provide comprehensive models for evaluation of academic staff [5]. The few reported studies that attempt to evaluate the overall activity of academics and the existing metrics do not capture the full range of activities that support and transmit scientific ideas [6]. Adaptation of modern education system has complicated the evaluation of the performance of the faculty because there are measures on a large number of variables, there may exist redundancy in those variables. Redundancy means that some of the variables are correlated with one another, as they are measuring the same "thing". Because of this redundancy character, it is possible to reduce the observed variables 
into a smaller number of variables. This opens the central issue of how to select or build the representative variables of each group of correlated variables. The simplest way to do this is to keep one variable and discard all others, but this is not reasonable.

Principal Components Analysis (PCA) is a variable reduction method that can be used to achieve the above mentioned goal. PCA as a multivariate analysis technique was first introduced by Pearson in 1901 [7] and developed independently by Hotelling in 1933 [8]. It is commonly used to eliminate collinearity and reduce the dimensionality of a data set with a large number of interdependent variables. Technically, this method delivers a relatively small set of synthetic variables called principal components that account for most of the variance in the original dataset. The specific goals of principal component analysis are to reduce a large number of predictor variables to smaller number of principal components and to provide a regression equation for an underlying process by using predictor variables. Principal components can be derived such that they are nearly uncorrelated or orthogonal. These new composite variables may then be used in subsequent analyses.

The two main uses of PCA are in (a) assessing the dimensional structure of a dataset [9] or (b) reducing a large number of variables into a smaller set of linear combinations (components) for subsequent analyses (e.g., multiple regression).

\section{Materials and Methods}

\subsection{Data}

In India, the University Grants Commission (UGC) has prescribed academic performance indicators (API) for performance appraisal of faculty of higher education institutions. The API includes four major criteria viz., teaching, co-curricular, research and extension, and feedback. Each of these major criteria has sub criteria under which the faculty performance will be evaluated. Teaching criterion includes classes taken as per schedule, extra classes taken, resource material provided to students, innovative teaching methodologies adopted. The co-curricular criterion includes examination duties carried out, professional development activities, administrative activities carried out by the faculty. Research and extension criterion includes contribution to research in terms of paper/poster presentation in national and international conferences, publications in renowned journals, chairing of sessions, organizing conferences, seminars, guiding students for research work and consultancy. The fourth criterion which is feedback collected from students, peers and heads of the department for each faculty. These scores are utilized as data for analysis in this research paper.

In this study, faculty from Medical, Dental and
Pharmacy disciplines from all cadres- professors, associate professors and assistant professors were included. The faculty academic performance indicator scores (API scores) with four major criteria and 22 minor/sub-criteria (Teaching-A1-A4, Co-curricular-B1-B3, Research-C1-C12 and Feedback-D1-D3) of 327 faculty were considered. Among these 22 parameters we have tried to reduce redundancy by employing PCA. The principal components thus obtained. We have 7194 data points from 327 faculty with 22 API criteria in four major criteria. Since the data volume was very high multivariate data reduction method was applied to understand the pattern of the faculty performance.

\subsection{Model}

The API scores of faculty for each of the 22 indicators were entered into MS excel sheet and used for the analysis. The SPSS software was used for the analysis.

The aim of the PCA method is the construction out of a given set of variables $X_{j}{ }^{\prime} s(j=1,2,3 \ldots k)$ of new variables $\left(\mathrm{p}_{\mathrm{i}}\right)$ called principal components which are linear combinations of the $X_{s}$.

$$
P C_{j k}=a_{j i} X_{k i}+a_{j 2} X_{k 2}+a_{j 1} X_{k 1}+\ldots .+a_{j n} X_{k n} \ldots \ldots .
$$

where " $\mathrm{PC}_{\mathrm{jk}}$ " is the score for object " $\mathrm{k}$ " on component " $\mathrm{j}$ ", " $\mathrm{a}_{\mathrm{ji}}$ " is the loading of a variable " $\mathrm{I}$ " on component " $\mathrm{k}$ ",

"ki" is the measured value of a variable "I" on object "k" and

" $\mathrm{n}$ " is the original number of variables.

The " $\mathrm{a}_{\mathrm{ji}}$ " are called loading and are worked out in such a way that the extracted principal components satisfy two conditions: (i) principal components are uncorrelated (orthogonal) and (ii) the first principal component $\left(\mathrm{p}_{1}\right)$ has the maximum variance, the second principal component $\left(\mathrm{p}_{2}\right)$ has the next maximum variance and so on. This decrease in dimensionality is achieved without loss of variance in the data. The principal components thus obtained were used instead of original variables for further analysis.

\subsection{Measures of Sampling Adequacy}

To ensure that the database was suitable for PCA, some tests of reliability and adequacy were performed. Kaiser-Meyer-Olkin (KMO) and Bartlett's Tests are used to calculate the correlation among all variables analyzed and also to verify the hypothesis of correlation matrix of variables is an identity matrix [10]. To determine the suitability of the sample for EFA Kaiser-Meyer-Olkin Measure (KMO) of Sampling Adequacy (cutoff above .50) and the diagonal element of the Anti-Correlation matrix that has the 'a' superscript (cut-off of above .50) are used. In this study, KMO was .758, showing that data are significant [11] and also Bartlett`s test is highly significant $(p<0.001)$, and therefore factor analysis is appropriate. 


\section{Results}

The descriptive statistics of the faculty performance scores with 22 parameters is shown in the table with the mean and standard deviation and the number of sample (n) in each indicator are presented in table 1 . From the table, it is observed that there is no missing value. The standard deviation also indicates that most of the values are in same size, which indicates that either correlation/ covariance matrix can be used and in this study, correlation method was used.

Table 1. Descriptive Statistics of the 22 parameters/indicators

\begin{tabular}{|c|c|c|c|}
\hline \multicolumn{4}{|c|}{ Descriptive Statistics } \\
\hline Parameters & Mean & Std. Deviation & Analysis N \\
\hline A1 & 51.0573 & 10.48322 & 327 \\
\hline $\mathrm{A} 2$ & 16.746 & 6.7228 & 327 \\
\hline A3 & 14.969 & 6.9991 & 327 \\
\hline A4 & 20.376 & 7.7052 & 327 \\
\hline B1 & 9.193 & 8.1174 & 327 \\
\hline B2 & 8.743 & 6.3281 & 327 \\
\hline B3 & 10.875 & 5.2091 & 327 \\
\hline $\mathrm{C} 1$ & 14.9223 & 26.19722 & 327 \\
\hline $\mathrm{C} 2$ & 1.103 & 5.8394 & 327 \\
\hline C3 & .982 & 3.8244 & 327 \\
\hline $\mathrm{C} 4$ & 1.254 & 10.5575 & 327 \\
\hline C5 & 1.432 & 4.8462 & 327 \\
\hline C6 & 1.360 & 4.9436 & 327 \\
\hline $\mathrm{C} 7$ & .384 & 1.9598 & 327 \\
\hline $\mathrm{C} 8$ & .986 & 5.5233 & 327 \\
\hline C9 & 2.495 & 4.8200 & 327 \\
\hline C10 & 1.898 & 8.0352 & 327 \\
\hline C11 & 4.289 & 10.9198 & 327 \\
\hline C12 & 3.209 & 7.3959 & 327 \\
\hline $\mathrm{D} 1$ & 27.7816 & 14.38195 & 327 \\
\hline D2 & 12.8001 & 6.02565 & 327 \\
\hline D3 & 11.3779 & 7.64130 & 327 \\
\hline
\end{tabular}


Table 2. Total Variance

\begin{tabular}{|c|c|c|c|c|c|c|c|c|c|}
\hline \multicolumn{10}{|c|}{ Total Variance Explained } \\
\hline \multirow{2}{*}{$\begin{array}{c}\text { Compo } \\
\text { nent }\end{array}$} & \multicolumn{3}{|c|}{ Initial Eigen values } & \multicolumn{3}{|c|}{ Extraction Sums of Squared Loadings } & \multicolumn{3}{|c|}{ Rotation Sums of Squared Loadings } \\
\hline & Total & $\begin{array}{c}\% \text { of } \\
\text { Variance }\end{array}$ & $\begin{array}{c}\text { Cumulati } \\
\text { ve } \% \\
\end{array}$ & Total & $\begin{array}{c}\% \text { of } \\
\text { Variance }\end{array}$ & $\begin{array}{c}\text { Cumulative } \\
\%\end{array}$ & Total & $\begin{array}{c}\text { \% of } \\
\text { Variance }\end{array}$ & $\begin{array}{c}\text { Cumulative } \\
\% \\
\end{array}$ \\
\hline 1 & 4.537 & 20.622 & 20.622 & 4.537 & 20.622 & 20.622 & 2.622 & 11.918 & 11.918 \\
\hline 2 & 2.986 & 13.572 & 34.194 & 2.986 & 13.572 & 34.194 & 2.553 & 11.605 & 23.523 \\
\hline 3 & 1.521 & 6.912 & 41.105 & 1.521 & 6.912 & 41.105 & 1.355 & 6.159 & 29.682 \\
\hline 4 & 1.244 & 5.653 & 46.758 & 1.244 & 5.653 & 46.758 & 1.262 & 5.734 & 35.416 \\
\hline 5 & 1.151 & 5.233 & 51.991 & 1.151 & 5.233 & 51.991 & 1.101 & 5.006 & 40.422 \\
\hline 6 & 1.084 & 4.928 & 56.919 & 1.084 & 4.928 & 56.919 & 1.090 & 4.956 & 45.379 \\
\hline 7 & 1.058 & 4.808 & 61.727 & 1.058 & 4.808 & 61.727 & 1.062 & 4.829 & 50.208 \\
\hline 8 & .988 & 4.493 & 66.220 & .988 & 4.493 & 66.220 & 1.054 & 4.793 & 55.000 \\
\hline 9 & .905 & 4.112 & 70.332 & .905 & 4.112 & 70.332 & 1.051 & 4.779 & 59.779 \\
\hline 10 & .881 & 4.004 & 74.335 & .881 & 4.004 & 74.335 & 1.036 & 4.709 & 64.488 \\
\hline 11 & .735 & 3.342 & 77.677 & .735 & 3.342 & 77.677 & 1.036 & 4.708 & 69.196 \\
\hline 12 & .674 & 3.063 & 80.740 & .674 & 3.063 & 80.740 & 1.035 & 4.707 & 73.903 \\
\hline 13 & .618 & 2.809 & 83.550 & .618 & 2.809 & 83.550 & 1.032 & 4.693 & 78.596 \\
\hline 14 & .554 & 2.517 & 86.067 & .554 & 2.517 & 86.067 & 1.010 & 4.590 & 83.186 \\
\hline 15 & .540 & 2.456 & 88.523 & .540 & 2.456 & 88.523 & .880 & 4.001 & 87.187 \\
\hline 16 & .517 & 2.349 & 90.872 & .517 & 2.349 & 90.872 & .811 & 3.685 & 90.872 \\
\hline 17 & .480 & 2.182 & 93.054 & & & & & & \\
\hline 18 & .457 & 2.075 & 95.129 & & & & & & \\
\hline 19 & .394 & 1.791 & 96.920 & & & & & & \\
\hline 20 & .337 & 1.531 & 98.451 & & & & & & \\
\hline 21 & .196 & .892 & 99.344 & & & & & & \\
\hline 22 & .144 & .656 & 100.000 & & & & & & \\
\hline
\end{tabular}

From the above table on total variance, we observed that seven components had latent root greater than one (Kaiser's), and were considered essential and retained out of the original 22 components. These seven components accounted for $61.72 \%$ of the total variance. The first component accounted for $20.62 \%$ of variance followed by the second component which accounted for $13.57 \%$ of variance and likewise.

Communalities: Communality explains the total amount an original variable shares with all the other variables included in the analysis and is useful in deciding which variables to finally extract [12]. The variances of the data extracted are compared with the variances of the original variables, checking how much variance in common (communalities) exists among observed variables and those obtained from the PCA model. The values of the communalities are set in the below table and all the 22 indicators presented values higher than 0.6 , indicating high representativeness of the indicators in the faculty evaluation. 
Table 3. Values Communalities of Indicators

\begin{tabular}{|c|c|c|}
\hline Indicators & Initial & Extraction \\
\hline A1 & 1.000 & .941 \\
\hline A2 & 1.000 & .905 \\
\hline A3 & 1.000 & .905 \\
\hline $\mathrm{A} 4$ & 1.000 & .818 \\
\hline B1 & 1.000 & .954 \\
\hline B2 & 1.000 & .907 \\
\hline B3 & 1.000 & .936 \\
\hline $\mathrm{C} 1$ & 1.000 & .940 \\
\hline C2 & 1.000 & .976 \\
\hline $\mathrm{C} 3$ & 1.000 & .976 \\
\hline $\mathrm{C} 4$ & 1.000 & .783 \\
\hline C5 & 1.000 & .988 \\
\hline C6 & 1.000 & .891 \\
\hline C7 & 1.000 & .984 \\
\hline C8 & 1.000 & .883 \\
\hline C9 & 1.000 & .912 \\
\hline C10 & 1.000 & .964 \\
\hline C11 & 1.000 & .783 \\
\hline C12 & 1.000 & .971 \\
\hline D1 & 1.000 & .884 \\
\hline D2 & 1.000 & .877 \\
\hline D3 & 1.000 & .813 \\
\hline
\end{tabular}

Extraction Method: Principal Component Analysis.

An alternative to Kaiser's rule is Cattell's (1966) scree test, which provides a graphical representation of the eigenvalues relative to their magnitude. The basic idea is to plot eigenvalues on the ordinate ( $y$ axis) of a bivariate scatter with order of magnitude represented on the abscissa ( $x$ axis). Then, a visual inspection of the scree plot is undertaken to identify a point at which an inflection occurs that signifies a flattening of the line of best fit. Eigenvalues that occur before the first value that signifies a flattening are then retained [13].

From the figure 1, we can see an abrupt decay curve and apparently stabilizes at values between 0 e 1 after the first 3 components, which represent an accumulated variance that exceeds $7 \%$ as seen in the table 1 . This result shows sufficiency on the representation of the original data [14]. The Scree plot (Figure 1) identified sixteen components with eigen value more than 1 and accounted for almost $90 \%$ of the variability in the original variable. The conventional rule about communality values is that eigen value of more than 0.50 from the initial iteration indicate that the variables are significant and should be included in the analysis [15]. Because eigenvalues represent reproduced variance, this is equivalent to setting a minimum level of acceptable variance reproduced by a component. The last six factors had single variables and could not be linked to the other factors and hence were dropped from the analysis. 


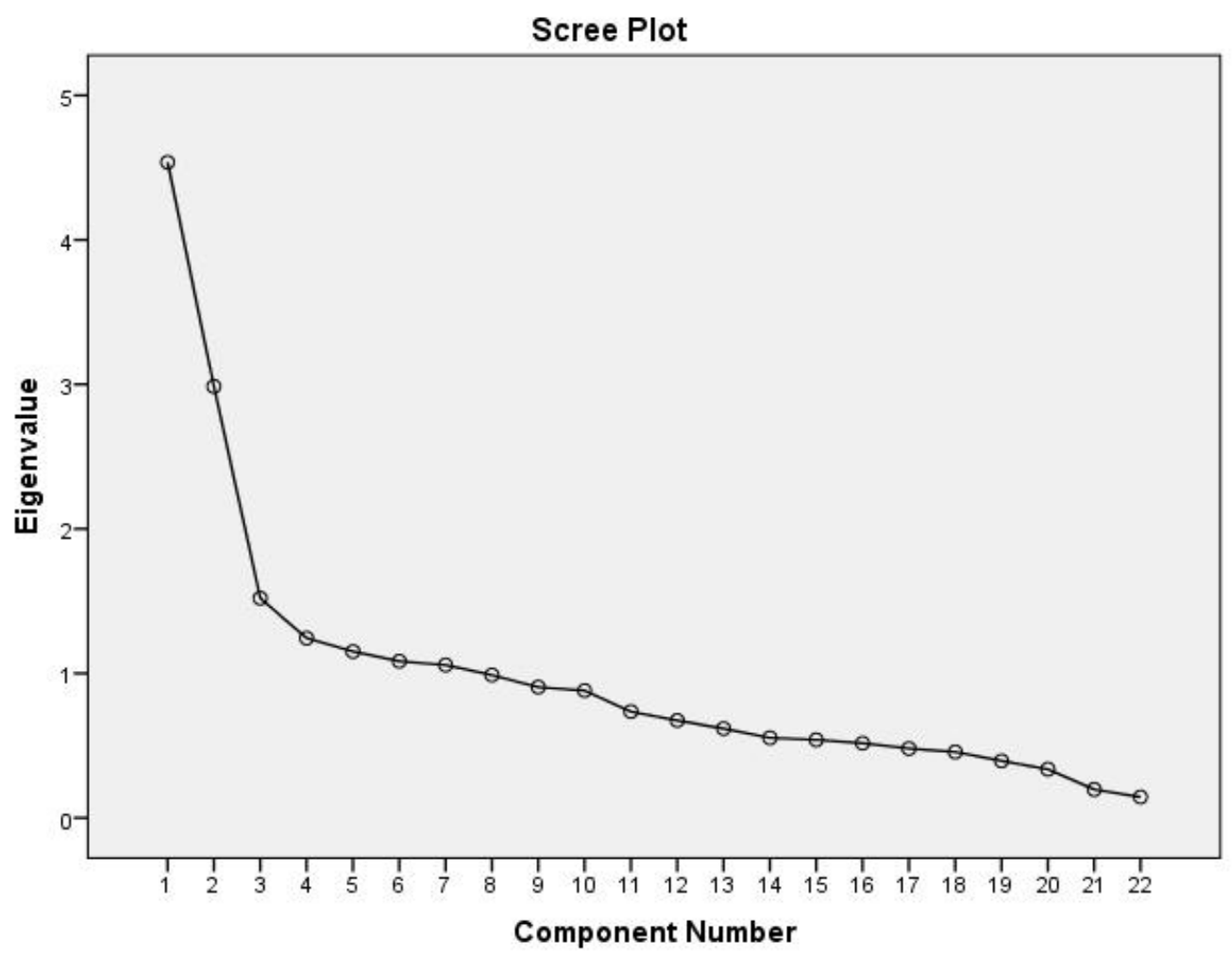

Figure 1. Scree plot of the API scores of faculty members

\section{Component Plot in Rotated Space}

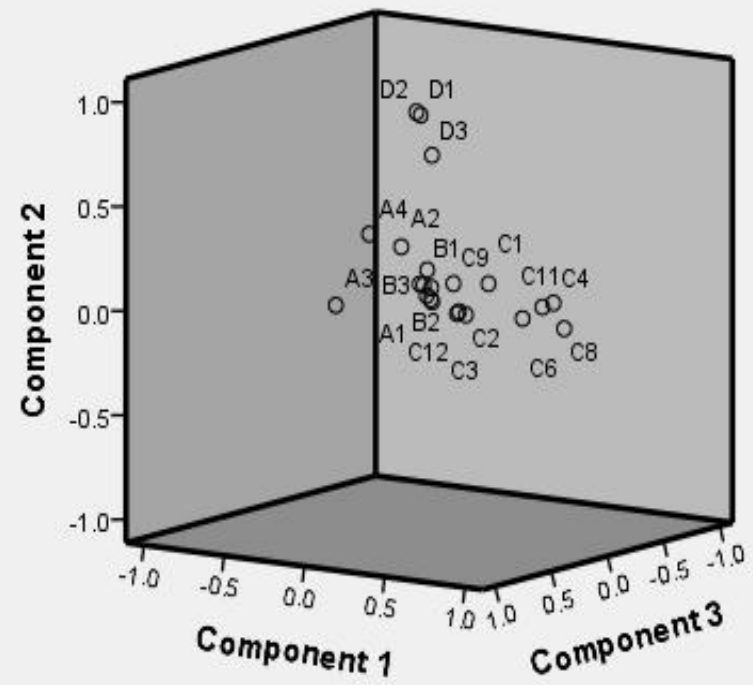

Figure 2. Component plot in rotated matrix for faculty performance analysis 
Component plot in rotated space also showed most of the components featured in component 1 and only A3 and A4 near component 2 .

\section{Discussion}

Principal Component analysis reduced the 7194 data points from 22 parameters of 327 faculty performance scores into seven principal components (PCs). The results showed that there was a correlation between the multiple variables (22 indicators) of API for faculty performance evaluation and only seven components could successfully explain the statistic variations in the data and model the output instead of using all the variables. The significance of these indicators on the overall performance was also established. Out of the seven principal components, the first component (PC1) significantly explained four variables (C8, C4, C11 and C6) which are consultancy, publications, conference presentations and projects whereas the second component (PC2) explained the three variables (D2,D3andD1) which is feedback obtained from students, peers and heads and the third component (PC3) explained the two variables (A3,A4) which are additional teaching material provided and innovative teaching methodology used by the faculty to be significan tin determining the variations in the statistical analysis. Likewise the seven principal components also reflected on the variables which had significance in faculty performance. The results clearly indicated which are the distinguishing factors for each faculty to be ranked higher than others in terms of their performance. The variables identified could serve as mapping of competencies of each faculty and help education managers organize training and development activities for the faculty.

The results of PCA showed which of the 22 indicators are important and faculty should focus on improving their performance across these parameters and thereby enhancing their quality of work. Management should also give emphasis for training of faculty in various activities rather than teaching alone. The role of a teacher in modern education is more of a facilitator and a disseminator and not mere teaching. This requires careful selection of faculty by education managers and identify faculty who can fulfill these requirements and promote them based on their performance.

The use of Principal component analysis to obtain composite scores is a valuable tool when dealing with correlated variables. From this study, the problem of multicollinearity which leads to some perplexing results can be overcome by the use of component scores which help to clarify these statistical dilemmas. In addition, the use of component scores rather than a large number of individual variables is better given the fact that, all other things being equal, using fewer predictors (in the regression case) makes for a more powerful analysis.

The fact that out of the 22 indicators seven of them showed significance implies that while assessing faculty performance weightage should be given to each of the criteria and not merely assess them based on overall score. The factors which did not show any significance may not have been given importance by the faculty as well as the education managers but which may have been important in the long run. This requires careful designing of parameters and a scientific and futuristic thinking from the education managers to assess faculty and also to align them for strategic growth and development of the organizations. The PCA approach is also useful for creating new variables that are linear combinations of a set of highly correlated original variables. These new composite variables may then be used in subsequent analyses.

\section{Conclusions}

The appraisal methods used for faculty performance evaluation have to consider multiple variables which represent the multiple activities carried out by faculty of HEI for providing reliable results. Considering the changing roles of faculty in HEIs in modern times it becomes essential for management of higher education institutions to adopt scientific methods for assessing performance of their most important human resource i.e., faculty. Decisions need to be based on reliable and validated results to provide transparency as well as confidence among assesses. Hence use of statistical methods like PCA to some extent provides reliable results considering multiple variables representing the parameters for faculty performance evaluation.

\section{REFERENCES}

[1] Tripathi, P \& Suri R. K (2010), Development of Competence based management and Performance Assessment System for Academic Management: Empirical Investigation, International Journal of Innovation, Management and Technology, Vol. 1(4), October 2010. Pp 357 - 361.

[2] Bhargava A., Pathy M. (2011). Perception of Student Teachers about Teaching Competencies. American International Journal of Contemporary Research. Vol. 1 (1): 77-81, Centre for Promoting Ideas, USA, www.aijcrnet.co $\mathrm{m}$.

[3] World Bank Report (2005), 'India and the Knowledge Economy; Leveraging Strength and Opportunities', The World Bank, Report number 31267-IN, April 2005

[4] Blackmore, P., \& Blackwell, R. (2003). Academic roles and relationships. In R. Blackwell \& P. Blackmore (Eds)., Towards strategic staff development in higher education (pp.16-28). Berkshire: The Society for Research into Higher Education (SRHE) and Open University Press.

[5] Elmore, H.W., (2008), "Towards Objectivity in Faculty Evaluation”, Academe, 94(3): 38-40 
[6] Julia Lane (2010), Let's make science metrics more scientific, Nature 464, 488-489 (25 March 2010), doi:10.1038/46448 $8 a$

[7] Pearson, K. 1901. On lines and planes of closest fit to systems of points in space. Philosophical Magazine 2:559-572. http://pbil.univ-lyon1.fr/R/pearson1901.pdf

[8] Hotelling, H. (1933). Analysis of a complex of statistical variables into principal components. Journal of Educational Psychology, 24(7), 498-520. http://dx.doi.org/10.1037/h00 70888

[9] George H. Dunteman (2001), Principal Components Analysis, Volume 69 of Sage university papers/ Series quantitative applications in the social sciences, Sage Publications.

[10] Tabachknik B.G., \& S.L. Fidell, (1996), Using multivariate statistics, (3rd edition), Harper Collins College Publishers. New York.

[11] Green, P. E. (2011). Multivariate Data Analysis. Cengage Learning

[12] Bakhru et. Al., (2013) A principal component analysis of teaching competencies required for management education, Arth Prabhand: A Journal of Economics and Management Vol.2 Issue 7 July 2013, ISSN 2278-0629.

[13] Stevens, J.P. (1992). Applied Multivariate Statistics for the Social Sciences (2nd edition). Hillsdale, NJ: Erlbaum.

[14] Vicente Cassepp, Luiz Pasquali (2012), Sternberg's Triangular Love Scale National Study of Psychometric Attributes, Paidéia jan.-abr. 2012, Vol. 22, No. 51, 21-31. www.scielo.br/paideia

[15] Field, A., (2005) Factor Analysis using SPSS: Theory and Applications, retrieved from http://www.sussex.ac.uk/esers /andyf/factor.pdf 